\title{
Ciencia de la información y archivística: un diálogo a partir de la información registrada
}

Ciência da Informação e Arquivística: um diálogo a partir da informação registrada

Information Science and Archival Science: a dialogue around the concept of recorded information

Natália Bolfarini Tognol (1), José Augusto Chaves GuIMARÃEs (2)

(1) Faculdade de Filosofia e Ciências - UNESP, Av. Hygino Muzzi Filho, 737 Marília - São Paulo - Brasil - CEP: 17525-900, nataliabtognoli@yahoo.com.br (2) guima@marilia.unesp.br

\begin{abstract}
Resumen
Las nuevas formas de producción de conocimiento en la "era de la información" han llevado a la Archivística a renovar su corpus teórico y metodológico para que pudiera adaptarse a esta nueva realidad. En ese ámbito emergieron en Canadá, a finales de los años 80 del siglo $X X$, nuevos abordajes para la organización del conocimiento archivístico, destacando la Archivística Integrada, que estableció un rico dialogo con la Ciencia de la Información y de la Documentación al definir la información orgánica como su objeto de estudio. Se busca, por lo tanto, caracterizar y analizar la Archivística Integrada y su objeto como punto de partida para el análisis de la relación entre la Archivística y la Ciencia de la Información a partir del concepto de información registrada.
\end{abstract}

Palabras clave: Ciencia de la Información. Archivística integrada. Información registrada. Información orgánica.

\section{Introdução}

A Ciência da Informação $(\mathrm{Cl})$ encontra em seu objeto de estudo um espaço de interlocução com as outras áreas do conhecimento. $A$ informação registrada é o elemento responsável por dar a ela um caráter interdisciplinar por natureza.

Nesse contexto, a $\mathrm{Cl}$ está relacionada diretamente às outras áreas da documentação, como a Arquivística, a Biblioteconomia e até mesmo a Museologia, embora a primeira só tenha admitido ter a informação como objeto de estudo a partir do final da década de 1980.

Essa visão do objeto da Arquivística é fruto da abordagem canadense conhecida como Integrada, proposta por Couture, Ducharme e Rousseau, em 1988, no artigo L'archivistique at-elle trouvé son indetité?, que busca integrar a disciplina - dividida na America do Norte durante a década de 60 - a partir do ciclo vital dos documentos e da identificação do novo objeto de estudo da área, a informação orgânica regis-

\begin{abstract}
New forms of knowledge production in the so-called "information age" have led Archival Science to renew its theoretical and methodological corpus so it can be adapted to this new reality. In this way, new approaches for archival knowledge organization have emerged in Canada since the late 80's, emphasizing here Integrated Archival Science, which has established a rich dialogue with Information Science and Documentation, when defined its object of study as organic information. Therefore, the purpose of this study is to characterize and analyze Integrated Archival Science and its object, as a starting point for analyzing the relation between Archival Science and Information Science from the dialogue established through the concept of recorded information.
\end{abstract}

Keywords: Information Science. Archival Science. Recorded Information. Organic Information.

trada, aproximando consequentemente, a $\mathrm{Cl}$ da Arquivística.

Pretende-se, com esse trabalho, expor as relações entre as duas disciplinas, com base no diálogo estabelecido por ambas a partir do objeto de estudo: a informação registrada. Para tanto, procedemos a uma breve caracterização da Ciência da Informação e da Arquivística Integrada, assim como a relação de interdisciplinaridade entre ambas, notadamente a partir do contexto científico brasileiro para, posteriormente, analisarmos e apresentarmos os resultados do trabalho.

Destaca-se ainda o fato de o presente trabalho buscar contribuir para as questões teóricas que circundam as áreas em questão, especificamente a Arquivística que, desde o final do século $X X$ e começo do XXI tem sido levada a repensar seu papel na chamada era da informação, devido às novas formas de produção documental $e$ as novas tecnologias de informação apresentadas à sociedade. 


\section{A Ciência da Informação e seu objeto: information-as-thing}

A Ciência da Informação estuda os processos de produção, organização e uso da informação. Ao partirmos da clássica definição de Borko (1968), podemos dizer que a mesma estuda as propriedades e o comportamento da informação e os meios para processá-la, de forma que ela possa ser acessada e utilizada corretamente.

No entanto, dizer que a informação é o objeto da $\mathrm{Cl}$ é uma afirmação passível de ambigüidade e desentendimento no mundo das chamadas ciências sociais aplicadas, uma vez que a informação é também objeto de outras disciplinas como a Comunicação, por exemplo.

Baseando-se nesse contexto, Buckland (1981) estabeleceu três sentidos para a informação: informação-como-processo (information-asprocess), informação-como-conhecimento (information-as-knowledge) e informação-comocoisa (information-as-thing).

$\mathrm{Na}$ última definição apresentada pelo autor reside o objeto mais palpável da Ciência da Informação (ou seja, aquele sobre o qual incidirão diretamente os processos da $\mathrm{Cl}$ ) e, consequentemente, da Arquivística. Aqui, o termo informação é utilizado para definir objetos, dados ou documentos cuja intenção é informar sobre alguma coisa.

Essa informação deve ser tangível e passível de organização, para que possa ser acessada e relacionada à $\mathrm{Cl}$ (Guimarães, 2008, p. 38).

Nesse sentido, Buckland resgata a ideia de documento preconizada por Paul Otlet no início do século $X X$ como designativo de um gênero de coisas informativas, pautada por alguma forma de materialidade, ou seja, de registro.

A ideia de documento como algo que informa e registra uma informação, é também objeto de estudo de Suzanne Briet, que em seu livro Qu'est-ce que la documentation, de 1951, estabelece a delimitação conceitual de documento enquanto evidência concreta ou simbólica, registrada e conservada, visando a representar, reconstruir ou provar um fenômeno físico ou intelectual. Para a autora, o documento pressupõe delimitação espacial e temporal, caráter permanente na medida em que conserva um conteúdo e inteligibilidade. Com isso Briet distingue fenômenos, objetos e criaturas (uma estrela no céu, uma pedra no rio) de objeto propriamente ditos (a foto da estrela, a pedra no museu). Logo, um objeto, um livro ou um documento pressupõem uma institucionalização para que possam ser considerados um objeto de museu, um livro de biblioteca ou um documento de arquivo.

Entende-se o documento arquivístico como aquele que foi produzido e/ou recebido por uma pessoa física ou jurídica no decorrer de uma função específica. Nesse sentido, é um documento que foi produzido com o objetivo de fazer cumprir uma ação, ou de comprová-la e que mantém uma relação orgânica com os outros documentos produzidos no mesmo contexto.

Desse modo, seguindo o raciocínio arquivístico e institucional, proposto por Briet, um registro isolado, fora de um contexto específico, não pode ser considerado um documento arquivístico, ou uma informação institucionalizada registrada.

\section{Arquivística e seu objeto: 0 documento de arquivo}

A Arquivística enquanto disciplina desenvolveuse tardiamente, somednte no século XIX, mas segundo alguns autores (Silva et al., 1999), as práticas arquivísticas datam da Antiguidade.

Seu desenvolvimento teórico deu-se a partir de reflexões de ordem pragmática, fruto da publicação de manuais específicos para organizar o material contido em arquivos públicos europeus.

Nesse contexto, princípios e conceitos emergiram para justificar a inserção da Arquivística no campo disciplinar, e para auxiliar os arquivistas a organizar o material que havia sido acumulado durante séculos nos arquivos de todo o mundo.

Destaca-se aqui a enunciação do princípio da proveniência e do conceito de fundo, elementos basilares para a construção da disciplina (Duchein, 1983, p. 64).

[...] O princípio da proveniência consiste em deixar agrupados, sem misturar a outros, os arquivos (documentos de qualquer natureza) provenientes de uma administração, de um estabelecimento ou de uma pessoa física ou jurídica determinada: o que se chama fundo de arquivo dessa administração, desse estabelecimento ou dessa pessoa.

Ainda no intento de inserir a Arquivística no campo disciplinar e científico, objetivou-se também identificar seu objeto de estudo, caracterizando-o como o registro de uma ação, que tem por objetivo produzir efeitos jurídicos e provar um fato. Esse registro é, portanto, o documento arquivístico.

Uma revisão de literatura nos permitiu observar e identificar o objeto da área, por meio do olhar de autores (Heredia, 1991; Lodolini, 2008; BeIlotto 2005; Duranti, 1995; Schellenberg, 2004; Couture, 1988) que se dedicaram exaustivamente ao assunto nas últimas décadas. Com 
exceção de Couture e Bellotto, todos identificaram o conjunto de documentos de arquivo como objeto da Arquivística.

Para Bellotto (2005, p. 5) o objeto intelectual da disciplina é a informação, mais precisamente os dados que possibilitam a informação. Segundo a autora, podemos considerar ainda que a Arquivística apresenta objetos físicos, entre eles o arquivo, ou seja, "conjunto documental produzido/recebido/acumulado por entidades públicas ou privadas no exercício de suas funções."

Nesse sentido, a definição que mais se aproxima do sentido proposto pela $\mathrm{Cl}$ é a de Couture e Rousseau (1982) ao definir o objeto da Arquivística como o "conjunto de informações orgânicas", quando propõem uma nova visão da disciplina, ao integrar todo o ciclo documental, ao que denominaram Arquivística Integrada.

\section{Arquivística Integrada e seu objeto: a informação orgânica}

A América do Norte conheceu, nos anos 50, novos conceitos e novas práticas arquivísticas para o tratamento da massa documental acumulada durante mais de um século pelas administrações públicas.

Essa nova realidade apresentada aos arquivistas gerou uma ruptura na teoria e na prática arquivística no momento em que separou seu objeto, o documento de arquivo, diferenciando-o para os record managers e o para os archivists. Nesse momento, cabia, portanto, aos record managers gerenciar a documentação corrente e intermediária produzida pelas instituições, enquanto que aos archivists estavam ligados os documentos que poderiam ser considerados de cunho histórico, permanente.

No entanto, a partir dos anos 80 , uma nova abordagem surge no Canadá francês com a intenção de reintegrar a disciplina, trabalhando novamente com todo o ciclo documental, dos documentos correntes até os permanentes. É a chamada Arquivística Integrada, cujos estudos estão baseados nas realidades europeia dos documentos históricos e norte-americana da gestão documental (1).

Nesse sentido, a Arquivística Integrada busca uma reintegração da disciplina, focando seus estudos na gestão da informação orgânica e em sua importância para o fortalecimento da disciplina no século XXI.

Essa abordagem integradora foi proposta primeiramente por Couture, Ducharme e Rousseau no final dos anos 80 , devido às necessidades enfrentadas pelo Arquivo Nacional do Québec em trabalhar com documentos ativos, semiativos e históricos (Couture; Ducharme; Rousseau, 1988, p. 53).

[...] assiste-se hoje no Québec, a um crescimento gradual do consenso quanto à necessidade funcional e até mesmo estratégica de unir em uma só profissão os profissionais do record management e aqueles da arquivística tradicional, em torno de noções, princípios e métodos comuns [...].

Aqui, a Arquivística e o arquivista não devem mais ser vistos como simples guardiões da memória histórica e institucional. Eles participam, agora, do momento de criação dos documentos, garantindo também uma racionalização da informação e de seus processos. A contribuição dos arquivistas para a gestão da informação, e a união das profissões em um só profissional "constituem a base da identidade moderna da disciplina" (Couture; Ducharme; Rousseau, 1988, p. 53).

É, portanto nesse contexto, que a informação começa a ter um papel mais ativo na disciplina, pois é um elemento fundamental para o funcionamento e desenvolvimento de qualquer organização e, por essa razão, deve ser gerida de forma eficaz.

Os termos informação orgânica e informação não-orgânica são frutos da abordagem quebequense. Aqui, a informação orgânica é definida como aquela que é produzida e/ou recebida no âmbito de uma atividade, e a produção de uma ou mais informações orgânicas darão origem aos arquivos da instituição. Já as informações não-orgânicas são aquelas contidas em documentos bibliográficos, como as publicações e os materiais de referências, por exemplo.

Além disso, a informação orgânica pode ter um valor primário e um valor secundário, correspondendo aos valores dos documentos de arquivo colocados primeiramente por Schellenberg (2).

Como consequência, a gestão de documentos também dará lugar à gestão da informação orgânica, que desempenhará um papel decisivo, no que tange à organização e disseminação das informações e à rapidez nos processos de tomada de decisão no interior das organizações.

Para que as organizações possam usufruir de um sistema de gestão que ofereça uma solução para os problemas gerados pela produção e acúmulo desordenado de informações, Couture, Ducharme e Rousseau (1988) criaram um programa em três fases, por meio do qual a Arquivística pode demonstrar sua grande contribuição no campo da gestão integrada da informação orgânica. (Rousseau; Couture, 1998, p. 68). 
A primeira fase corresponde à produção, difusão e acesso à informação orgânica, onde a informação é concebida de maneira estruturada e inteligível. É registrada em um suporte adequado, sendo posteriormente inserida no canal de difusão apropriado, a fim de ser facilmente acessível e de permitir uma comunicação máxima que tenha em conta tudo quanto do ponto de vista legal, cultural e tecnológico [...] A segunda fase componente do programa diz respeito à classificação e à recuperação da informação [...] a terceira e última fase centra-se na proteção e na conservação da informação. A informação bem protegida e conservada segundo normas técnicas e materiais precisas pode ser facilmente comunicada

É justamente por meio da implantação de um programa que englobe a produção, a difusão e acesso, a classificação, a recuperação e a preservação da informação que a Arquivística poderá exercer seu papel no seio da gestão da informação, apresentando seu novo papel, integrando todas as fases do ciclo vital dos documentos, assegurando uma unidade e continuidade no trabalho arquivístico.

Nesse sentido, segundo Rousseau e Couture (1998, p. 70) a Arquivística Integrada possui três objetivos:

- garantir a unidade e a continuidade das intervenções do arquivista nos documentos de um organismo, permitindo, assim, uma perspectiva do princípio das três idades e das noções de valor primário e secundário;

- permitir a articulação e a estruturação das atividades arquivísticas numa política de organização de arquivos;

- o valor primário e o valor secundário numa definição expandida de arquivo

Observa-se, portanto, que ao definir o objeto da Arquivística como a informação orgânica registrada, a abordagem quebequense busca inserir a disciplina na chamada "era da informação", integrando gerenciador de documentos (ativos e semi-ativos) e arquivista (documentos permanentes) em uma só profissão, de maneira a garantir a sustentação da Arquivística em um novo contexto de produção de informações.

Uma disciplina que quer ser reconhecida socialmente deve se esforçar ao máximo para construir um conjunto de conceitos, teorias e práticas globais, ao invés de fragmentá-los em duas disciplinas 'opostas', como ocorrera até então com a Arquivística tradicional e a gestão de documentos.

A proposta dos teóricos do Québec é um ponto de partida para uma consolidação da Arquivística enquanto uma disciplina integrada e autôno- ma, capaz de oferecer as soluções para os problemas colocados às organizações na era da informação, no que tange à produção e organização de informações orgânicas registradas.

\section{Ciência da Informação e Arquivística: uma perspectiva dialógica a partir do universo científico brasileiro}

No Brasil, na estrutura das agências de fomento à pesquisa a Ciência da Informação está inserida nas denominadas "Ciências Sociais Aplicadas", englobando a Arquivística, a Biblioteconomia e a Museologia, denominadas por Smit (1993) como "as três Marias".

Essa visão coloca a $\mathrm{Cl}$ como uma grande área, uma disciplina científica que rege as práticas arquivísticas, biblioteconômicas e museológicas. Seu objetivo, como colocado mais acima, é garantir que a informação registrada e institucionalizada possa ser acessada e disseminada de maneira rápida e eficaz.

Nesse contexto, a Arquivística e as outras disciplinas citadas, emergem como práticas de uma ciência maior. A Cl propõe um objetivo: estudar os processos de produção, organização e uso da informação, enquanto que as outras disciplinas colocam em prática esses processos. Como bem destacou Guimarães (2008, p. 33).

[...] há de se ter em conta que a Ciência da Informação, enquanto área de estudos, encontra fulcro em um conjunto de práticas que, no decorrer, ao longo do tempo, foram se consolidando, no mais das vezes ligadas a fazeres específico contextualizados em ambiências específicas.

Especificamente no campo arquivístico, essa visão é ainda muito discutida. Em alguns países, como França e Itália, os cursos de Arquivística estão inseridos em departamentos de História nas Universidades, ou em Arquivos Históricos.

A realidade brasileira constitui uma exceção. No Brasil os cursos de Arquivística, assim como os de Biblioteconomia, estão inseridos majoritariamente nos departamentos de Ciência da Informação nas Universidades, o que demonstra uma busca por aproximar, disciplinas relacionadas visando a uma construção Interdisciplinar em $\mathrm{Cl}$, ao menos, em sua estrutura.

Essa visão só é possível a partir do diálogo estabelecido entre as disciplinas, com base na informação registrada. Como bem destacou Smit (2000, p. 28), a relação é estabelecida quando a ênfase passa a ser dada na informação, e não apenas no documento. 
Nesse contexto, "documento e informação constituem as duas faces da mesma moeda [..] sendo impossível descolar as faces da moeda" (Smit, 2000, p. 30).

Desta feita, a realidade arquivística brasileira encontra nos conceitos enunciados pela Arquivística Integrada um espaço de interlocução, uma vez que desde a década de 1970, trabalha com o ciclo vital dos documentos como parte de uma única área, relacionando-se com a $\mathrm{Cl}$ à medida que estabelece com ela um diálogo a partir do binômio documento/informação registrada.

\section{Conclusão}

Buscou-se com esse trabalho, apresentar o elemento responsável pela interdisciplinaridade da $\mathrm{Cl}$ e da Arquivística: a informação registrada.

Nesse contexto, destaca-se a enunciação da Arquivística Integrada como um dos fatores responsáveis em estabelecer essa relação, à medida que traz à Arquivística uma nova visão de seu objeto de estudo, contribuindo para uma renovação da disciplina face às mudanças ocorridas no final do século XX e começo do XXI.

A abordagem canadense demonstra ainda, ao identificar a informação orgânica registrada como seu objeto de estudo, que o binômio documento/informação não é uma exclusividade da Biblioteconomia ou da Museologia, e que, o arquivista, pode e der tratar a informação como elemento central de seu trabalho.

Observa-se também que, a realidade arquivística brasileira é privilegiada por estabelecer essa relação a partir da inserção dos cursos de Arquivística nos departamento de Ciência da Informação nas Universidades, demonstrando ao menos, uma proximidade administrativa entre ambas as disciplinas.

Dessa forma, documento/informação não devem ser dissociados ao tratar das ciências da documentação, uma vez que a informação deve ser registrada em um suporte, para que possa ser processada, organizada e utilizada (processos nucleares da $\mathrm{Cl}$ ).

Concluí-se, portanto, que a Arquivística, uma disciplina relativamente nova e baseada fundamentalmente na prática, encontra na Ciência da Informação - especificamente no cenário brasileiro um espaço científico capaz de fundamentar a produção, a organização e o uso da informação orgânica registrada, em outras palavras, informação arquivística.

\section{Notas}

(1) A Arquivística Canadense é representada também pela Arquivística Pós-Moderna, proposta por Terry Cook, e pela Diplomática Arquivística, proposta por Luciana Duranti. No entanto, optamos nesse trabalho em estudar apenas a Arquivística Integrada, uma vez que esta é a única que apresenta um diálogo mais claro com a Ciência da Informação.

(2) O valor primário corresponde ao uso que a própria entidade produtora faz do documento, e o valor secundário corresponde ao uso que outras entidades ou pessoas farão do documento podendo ser dividido em: valor probatório e valor informativo.

(3) Optamos, nesse trabalho, por selecionar apenas um autor em cada país - citado pela comunidade científica da área - que tenha realizado obras e trabalhos importantes, constituindo-se marco teórico da Arquivística

\section{Referencias}

Bellotto, Heloísa L (2005). Archivística, archivos y documentos. São Paulo: ARQ-SP, 2005.

Borko, H. Information Science: what is it?. // American Documentation. 19:1 (Jan. 1968). 3-5.

Briet, Suzanne (1951). Qu'est-ce que la documenation? Paris: Edit, 1951.

Buckland, Michael K (1991). Information as thing. // Journal of the American Society for Information Science. 42:5 (June 1991) 351-360.

Couture, Carol; Ducharme, Jacques; Rousseau, Jean-Yves (1998). L'archivistique a-t-elle trouvé son identité? // Argus, 17:2 (1988) 51-60.

Couture, Carol; Rousseau, Jean-Yves (1982). Les archives aux XX siècle: une réponse aux besoins de l'administration et de la recherché. Montréal: Université de Montréal, 1982

Duchein, Michel (1983). Theoretical Principles and Practical Problemas of Respect des fonds in Archival Science. // Archivaria. 16 (Summer 1983) 64-82.

Duranti, Luciana (1995). Ciencia Archivistica. Córdoba, 1995.

Guimarães, José Augusto Chaves (2008). Ciência da Informação, arquivologia e biblioteconomia: em busca do necessário diálogo entre o universo teórico e os fazes profissionais. // Guimarães, J.A.C; Fujita, M.S.L. (eds.). Ensino e pesquisa em biblioteconomia no Brasil: a emergência de um novo olhar. Marília: Cultura Acadêmica e Fundepe, 2008. 33-43.

Heredia, Antonia Herrera (1991). Archivística General: teoría y práctica. $5^{\mathrm{a} e d}$. ampl. Sevilla: Servicio de Publicaciones de la Diputación de Sevilla, 1991.

Lodolini, Elio (2008). Archivistica: principi e problemi. 13a Ed. Milano: FrancoAngeli, 2008.

Schellenberg, Theodore Roosevelt (2004). Arquivos Modernos: princípios e técnicas. $2^{a}$ ed. Rio de Janeiro: FGV, 2004.

Silva, Armando Malheiro da; et al. (1999). Arquivística: teoria e prática de uma ciência da informação. Porto: Edições Afrontamento, 1999.

Smit, Johanna W. (1993). O documento audiovisual ou a proximidade entre as três Marias. // Revista Brasileira de Biblioteconomia e Documentação. $26: 1$ (1993) 81-85.

Smit, Johanna W. (2000). Arquivística, Biblioteconomia e Museologia: o que agrega estas atividades profissionais e o que as separa? // Revista Brasileira de Biblioteconomia e Documentação. 1:2 (2000) 11-26. 
Recibido: 12-04-2010. Revisado: 16-06-2010

Aceptado: 15-07-2010. 